\title{
Empowering Teachers: Building Sustainable Societies
}

\author{
Osaretin Osadolor, $\mathrm{Ph} . \mathrm{D}^{1^{*}}$ \\ ${ }^{1}$ Department of Educational Foundation and Management, Faculty of Education, Ambrose Alli \\ University, Ekpoma, Edo State, Nigeria \\ *Osaretin Osadolor, Ph.D, E-mail: osadolorosaretin@yahoo.com
}

\begin{abstract}
Teacher is whoever earns a living on teaching in the schools. However, in these modern times, teachers are change agents required for the realization of the national goals of education. Education has been described as the door to be opened to get national development. That being the case, the key for opening the door is the teacher.

National development may be far-fetched if issues inherent in sustainable societies are not addressed. Such issues include those which pre-disposes societies to unsustainability. They are; balance between economic system and ecosystem, according the environment its recognition, differentiating between growth and development, among others.

In order that the teachers may be well equipped to contribute towards bringing about sustainable societies, their acquisition of generic skills were canvassed as imperatives. The generic skills are; knowledge, communication skills, adaptability, creativity, team spirit, literacy, IT-Fluency, learning as a way of life.
\end{abstract}

\section{Keywords}

teachers, sustainable societies, generic skills

\section{Introduction}

Teaching can be described as series of activities which involves presentation of prepared and packaged body of knowledge and skills on specified topic by an individual called teacher to group of persons called learners. By this description, it means teaching is a transitive verb. Hence to teach means to do something to a person or a group of persons. The essence of teaching therefore, is subsumed in the several attempts and efforts which are aimed at making education truly functional and in these modern times, it is anchored on the human capital theory.

The Teacher: Arising from the description given to teaching above, it is obvious that; whoever is teaching the others is a teacher. The teacher in this context is a vacationer of all ages. As far back as the days of the ancient Greek, Socrates, Plato, Aristotle were already known as teachers. In their times, their thoughts, beliefs and teaching affected their societies and even beyond. Jesus Christ was a teacher because he taught multitudes (John, Vol. 3, p. 2). Prophet Mohammed taught and all his topics can be found in the Qur'an and Hadiths. 
In an ordinary term, the teacher is whoever earns his living on teaching in the school, whether trained for the job or not (Ngwu, 2009). The forgoing meaning is however misleading particularly in this era of knowledge driven society. Since teachers in these modern times are expected to be the agents being used to realize the national goal of education, teachers therefore cannot be any one who teaches in a school. In this connection, the teacher is a professional who has undergone the requisite training programme, and duely certified by the training institution. He is also expected to be a registered member of the Teachers Registration Council of Nigeria.

Education has been acclaimed as the doors to be opened to get national development in Nigeria (FRN, 2004). That being the case, the key for opening the doors are the teachers. By implication, the teachers stand out clearly and tall as the key for unlocking national development. Indeed the teachers are the curriculum engineers.

In appreciation of who a teacher is, the Federal Government of Nigeria affirms that no education in any nation can be beyond the quality of her teachers (FRN, 2004). Arising from that, it is obvious that the teacher is not just an ordinary vacationer. Hence the same policy document went further to state that the goals of teacher education shall be:

1) To produce highly motivated, conscientious and efficient classroom teachers for all levels of our educational system;

2) Encourage further the spirit of enquiry and creativity in teachers;

3) Help teachers to fit into social life of the community and the society at large and enhance their commitment to national goals;

4) Provide teachers with the intellectual and professional background adequate for their assignment and make them adaptable to changing situations;

5) Enhance teacher's commitment to the teaching profession (FRN, 2004).

A cursory examination of the policy statements enumerated above reveals Nigeria preparedness for a vire and sustainable society. And within such society, have, hold and maintain teachers that will stand the test of time.

\section{Sustainable Society}

Viederman (1993) wrote of a sustainable society as one; that ensures the health and vitality of human life and culture and of nature's capital, for present and future generations. The scholar added that a sustainable society acts to stop the activities that serve to destroy human life and culture and nature's capital, and to encourage those activities that serve to conserve what exists, restore what has been damaged, and prevent future harm.

While assuming that the concept of human life and culture are understood, it is however pertinent to briefly restate that nature's capital is the "stock that yields the flow of natural resources". Such resources as the population of grass cutters that regenerates the commonest and valuable "bush meat" in Southern part of Nigeria. It also include trees and shrubs that reproduce to add values to an economy 
and healthy environment. The yield of nature's capital include, both natural resources such as air, land, water, minerals, etc., and natures services such as efficient waste disposal and treatments. In effect nature's capital is renewable.

In pursuance of his belief in sustainable society, Viederman (1993) comments that under the prevailing paradigm, the world has achieved new languages of polities which negate immoral senses and have limited relevance to real economic circumstances, and in the process have ignored values and ethics. He opined that; what is needed is a new politics and a new economics, an ecological economics that bridges the economy and environment, and between people and nature.

\section{Indices of Unsustainable Society}

1) Increase in consumption of mass of plant materials by human economy. Today, human economy consumes about $40 \%$ of mass of plant materials, when indeed it is only one of the five to 30 million species that should make use of it on earth. In the past 35 years, consumption rate of plant materials by man in different ways is put at about $2 \%$ per year.

2) Global warming.

3) Depletion of Ozone layer.

4) Land and soil degradation, and their irreversibility in our life time. Soil loss in said to have exceeded soil formation and $35 \%$ of our land is also said to have been degraded.

5) Loss of biodiversity. World richest habitats are said to have been destroyed by over $55 \%$, while present day extinction rate is put at 5,000 species per year.

6) Rise in poverty level of people across the countries of the world. Even in wealthy market oriented and industrial economics of the world, over 100 million people are confirmed to be living in abject poverty (Mayer, 2014).

\subsection{Factors Pre-Disposing Societies to Unsustainability}

These are indeed sources of unsustainability of the societies. They have arisen as a result of our failure: 1) to balance the economic system with the ecosystem. It should be noted that economic system is an open system in a closed ecosystem.

2) to accord our environment its recognition as the basis of life.

3 ) to accept nature as a gift and a model that should regulate activities of mankind.

4) to appreciate the place of technology, believing that, it is answers to all problem.

5) to differentiate between growth and development.

6) to realize that there cannot be any conservation of nature's capital without justice and equity.

7) to give fair considerations to future generations, whose well-being in the basis of sustainable society. Teachers are co-builders on sustainable society site. However, the question which is worth contending with is how does the teacher function in a sustainable society and or work for attainment of sustainable society? Looking at what characterizes a sustainable society, it is obvious that ours is not yet one. In the circumstance, the teacher is unarguably being involved to contribute towards building a sustainable 
society. The questions which arose therefore are; how is the society within which the teacher is expected to work for its sustainability now? Also, how can the teacher be used as an instrument for attainment of a sustainable society?

Obanya (2014) describes today's new world as been rendered exceedingly complex as a result of factors of acceleration of History, Digital Revolution, Globalization, knowledge Economy and Climate of Pervasive Uncertainty. In addition, and particularly in Nigeria, crimes which are inimical to development have assumed an alarming dimension. While coping with the complexities of the new world, the teacher as an instrument would need to acquaint himself with some fundamentals which are critical to building sustainable societies.

It has been noted that teachers are not the only labourers that can be found working on the site for sustainable society. Suffice it to state that; the teacher's role in the exercise is critically an essential. Hence they need to be truly effective in their assignments.

An effective teacher, according to Clark (1993) and Sullivan (2001) is one who demonstrates knowledge of curricular, provides instruction in a variety of approaches to varied students, and measurably increases student achievements. All that are required is the equipment of the teacher in a manner that will enable him demonstrate mastery of the curriculum and provide instructions in varieties of approaches which were already accomplished as a result of training exercises. However, it does appear that, a lot are still required if teachers must function properly in his efforts to build a sustainable Nigerian society. Therefore, it has become necessary to present to teachers, who they should be in this $21^{\text {st }}$ centu.

\section{Pre-Requisite for Building Sustainable Society}

Damentals which are pre-requisites for bringing about national development. In other words, a sustainable society may be attained only when these pre-requisites, some of which are domiciled in the human capital theory are embraced.

The proponents of the human capital theory had posited that an investment in education brings about increase in productivity of the work force of the nation. Since teachers are already in the world of work, it is only logical that; they as learners be well persuaded by the theory, as they go about their practices, re-training and on the job training programmes.

In this connection, it is expected that the teacher should direct their activities at ensuring that;

1) They acquire the relevant parts of the knowledge which previous generations had already acquired,

2) Learn how existing knowledge can be applied to develop new products through new processes and methods to improve the efficiency of schools as business outfits,

3) Develop new ideas, production processes and methods through creativity based on thinking and aimed at problem solving.

In Exodus 20:3-14, the dos and don'ts on issues of life were given onto men through Moses. In the same vein, it has become necessary to present unto the teachers, Obayan (2014) summary of Generic 
Skills, which he said have arisen as a result of an attempt by education authorities in the various parts of the world to define "a new graduate profile". They constitute what should be in the present day teacher. The profile, according to him, is expected to help educational institutions to work towards building the skills of the future into their curricula. He added that; the rapid changes engendered by the knowledge economy and the consequent new work place requirements give rise to research efforts which were aimed at identifying the twenty-first century skills to be inculcated through education. Since teachers and future teachers in the schools are graduates who should be on continuous learning platform, the generic skills requirements have become imperatives for them in the circumstance.

The skills are as follows:

* Knowledge: in the form of versatility and flexibility, not simply the ability to store and reproduce facts and figures.

* Communication Skills: capacity to appreciate the views and feelings of others, to convey one's own feelings and opinions in ways that help to sustain personal and working relationships.

* Adaptability: a willingness to venture into novel situations-new ideas, novel working and living conditions, new knowledge areas, new working and thinking tools.

* Creativity: a strong drive to go beyond the well-trodden path.

* Team Spirit: an acceptance of the principles of group cohesiveness, the team being more important than any of its individual members.

* Literacy: in its comprehensive dimension prose, quantities, graphics, spatial-analysis, interpretation, use in communication.

* IT-Fluency: a mastery of ICT as thinking, research, communication, and working tool.

* Learning as the Way of Life: a frame of mind that is the foundation stone of life-long and life-wide learning.

As stated earlier, the rapid changes engendered by the knowledge economy and the consequent new work place requirements gave rise to research efforts that was coordinated by the University of Melbourne. (Obanyan, 2007) According to him, the work started with a group of more than 250 researchers across 60 institutions worldwide. Finally, the group summarized and categorized the $21^{\text {st }}$-century skills internationally into four broad categories:

- Ways of Thinking: Creativity, critical thinking, problem-solving, decision-making and learning,

- Ways of Working: Communication and collaboration,

- Tools for Working: Information and Communications Technology (ICT) and information literacy,

- Skills for Living in the World: Citizenship, life and career, and personal and social responsibility. 


\section{Gerian Teachers in the Twenty-First Century}

Izogie (2014), once asked his audience in a faculty seminar, if they knew those teaching their children in the schools? Although, the question appeared philosophical, it never the less sought to direct his audience to find out who the Nigerian teachers were.

Using the four broad categories summarized and categorized as the $21^{\text {st }}$ century skills requirements as criteria, the present day teachers in schools in Nigeria were assessed as follow:

\subsection{Way of Thinking}

This encompasses creativity, critical thinking, problems solving, decision making and learning. All of the above terms can also be summed up as creativity. Relying on the Wikipedia dictionary, Osadolor (2015) opined that; creativity as an attribute of man can evolve only with sharpened powers of insight and foresights that are powered by minds which have enough capacity for verification, criticism, analysis and relatively universally acceptable judgments. He added that; a cursory look at the concept of creativity indicates that whatever may have brought about development in our contemporary society and even before have come in as a result of creativity.

It has been observed and regrettably too, that after several years of schooling, Nigerian graduates, including teachers in the schools, usually do not know the appropriate steps to take in life when confronted with problem (Oyedipo, 2006; Imasuen, 2010; Tamiyi, 2013). It has also been noted that; over the years, policies on education placed teachers in position of only compliance with pre-determined teaching format and techniques that would bring about desired level of learning outcomes. In this regards, Markley (2006) remarked that teachers are being viewed as labourers implementing a prescribed programme in a manner determined by policy makers further up the educational hierarchy rather than as professionals with a repertoire of techniques and the ability to decide for themselves how techniques should be applied. Consequent upon the circumstances of the training given to the teachers and the policies regulating their practices, it is obvious that; teachers in the Nigeria school system are those with less creative minds and thinking.

\subsection{Ways of Working}

This refers to the communication methods used among the teachers, school heads and students/pupils in sending and receiving messages in the schools. It also includes assessment of the level of cooperation which exists among the teachers, management and student/pupils aimed at getting the goal of the school realized.

Okem (2014) examined the communication skills of teachers in secondary schools in Imo, Delta and Ekiti States of Southern Nigeria. His findings revealed that; 67.6 percent of the teachers were still used to the traditional formal system of communication in the schools. He added that only 32.4 percent of them understood and use the social media as means of communication. The above finding has also been collaborated by Hakeen (2015), when he stated that teachers at the basic and secondary education levels in Oyo State desire to shift from their traditional ways of communicating with the learners to what technology and modern sciences have offered. 
In terms of collaboration, Mogbolu (2013) noted that teachers in the school systems do not appreciate the need to reach out to colleagues and resource persons in their local environment for improved instructional delivery. In the same vein, Ngwu (2015) quarried school principals for non-encouragement of collaboration among teachers in their schools. He asserted that; certain topics in Agricultural Science, Biology and Technology could be taught cooperatively by teachers in these fields. According to him, evidences were abound to the effect that; teachers in Economics handle Economics related topics in Agricultural Science better than those trained as teachers of agriculture.

Based on the foregoing, it can be concluded that teachers in the Nigerian school system deserve improvement in their ways of working. This is because they seem to be defective in communication and collaboration which are essential requirements in the present day schools.

\subsection{Tools for Working}

This implies acquisition of the relevant knowledge and skills in information literacy and Information Communication Technology (ICT). Osadolor (2008) noted that staff and students personnel in secondary schools in Edo State were either not using computers and information communication facilities for conduct of their business or the level of use to which they were put was very minimal. He added that; the situation was highly regrettable, as it confirmed Osadolor (2006) assertion that public institutions were always less prepared in meeting the changing institutional needs as well as those of students and the society.

Ibe (2008) reiterated Nwosu (2003) position that; the masses in Nigeria education system were yearning for teaching and learning that were ICT compliant to enable learners meet the challenges of an information age. According to him, the pre-service teacher trainers did not adequately integrate ICT in the teaching and learning process.

In conclusion, he maintained that; his finding was in consonance with that of Nworgu (2006) that; the issue of adoption of ICT in the Education Sector was trailing behind other sectors like business and industry.

Even at the tertiary level of education, Ezeugbor (2008) reported that majority of the lecturers $(70 \%)$ had low competence and level in basic computer knowledge. As a result, the situation was negatively affecting the ability of the lecturers to harness the ICT gains in education. The report was in conformity with those of Yusuf (2005) and Olulube, Odogu and Ossai (2006) who found from their studies that Nigerian lecturer's ICT competence was below expectation. In conclusion, Ezeugbor (2008) opined that the situation was not surprising as most lecturers had demonstrated a lack of understanding of the basic skills associated with computer proficiency; hence they have failed to use them in teaching and doing other businesses of the school.

\subsection{Skills for Living in the World}

These entails career prospecting, personal and social responsibilities, all of which can be subsumed in good citizenship. Citizenship is a special status that is given or accorded to individuals by the State. It is acquired by birth, registration, marriage and nationalization. Therefore, a citizen is a person who is a 
member of a community in a country that enjoys the full legal, political and social rights in that community and in return performs certain duties to the state or community.

The duties of a citizen are actually the persons' personal and social responsibilities to the state. Oyelami, Abayomi, and Olatunde (2013) made a list of what constitute responsibilities of a citizen as follows: (1) protection of public properties, (2) payment of taxes and other levies, (3) obedience to rules, regulations, laws and constituted authorities, (4) loyalty and patrioticism, and (5) hard work. To the immediate community, a citizen should among others; promote peace, ensure security, preserve culture, and ensure proper use of publicly provided amenities, the scholars further posited.

The main question which arose at this point is; to what extent do teachers demonstrate good citizenship? Umalele (2013) and Iloi (2015) observed that teachers in the lower and middle basic schools lacked the requisite zeal demanded by their profession. They added that in the public schools, instead of the teacher to devote their time and expertise to teaching, the female teachers engage in trading while their male counterparts go about other businesses during school hours.

There have been public outcries about teachers' poor attitude to work. Also in Edo State, there is obvious paradox of teachers' shortage in schools in the rural areas and surplus in the urban areas. This is because, teachers decline posting to schools located in the rural districts. For those who accept such postings, they do the work haphazardly, just as their rate of absenteeism from the school is alarming. Teachers decline of posting to schools in rural districts, absence from schools and general nonchalant attitude to work in the public schools can be summed up as an unpatriotic act and lack of personal and social responsibilities on their part. Moreover, the presence of teachers is hardly noticed these days when community issues are being handled.

\section{Dilemma of the Nigerian Teacher in Working for Sustainable Society}

Teachers as labourers working with other vacationers in pursuance of sustainable societies may have to contend with certain inertias imposed on them by such factors as:

\subsection{Poor Quality Background}

As teachers in the various classrooms exit, particularly; due to pensions or retirements, the vacuum created will have to be filled with "incoming colleagues". It has been speculated that these "new colleagues" coming into the system are of low qualities in content and perception, at least when compared with those exiting (Obinna, 2003; Kayode, 2008; Mogbuelo, 2014).

At the moment, the entry requirements for those seeking admission into teacher education programme provided by tertiary schools is about the least when compared with others. The situation has even degenerated to such that; majority of those who are eventually offered places in teacher education programmes are those who could not gain entrance into other disciplines. Most worrisome is that, those offered places are further spoilt by the poor quality training given by the various teacher education institutions. It can be asserted that; examination malpractices, and other associated corrupt practices in the system, have made teacher education programmes in many institutions a "watery exercise". 


\subsection{Politicization of School Management}

Recruitment, posting and promotion of teachers have become highly politicized in the public schools sector. In the same vein, the management of the teaching staff personnel in the private schools have also been left in the whims and caprices of unprofessionally trained school owners to handle.

\subsection{Gender Issue}

Teaching as a vocation allows for both male and female as staff personnel. So far, no quota is spelt out with regards to the employment of both sexes into the field. Consequently, the ratio of teachers, particularly in the public schools is skewed positively in favour of the female teachers especially in the urban areas. It should be recalled that, for teachers to be able to find themselves as veritable instrument for attaining sustainable society, they will have to be involved in some sort of struggles. In a female dominated vocation such as teaching, attainment of success in such struggles may be remote, since women do have limitations as a result of the circumstances of their creation.

\subsection{Uncontrolled Participation of Private Sector}

Although, the government invited the private sector into sharing of the burden of providing education for those in need, their participation has however brought disrepute to the teaching vocation. This is because, the sector appoint unqualified persons as teachers, thereby casting poor aspersions on the nobility of the profession. In the same, the poor quality services provided by such teachers can hardly bring about the much sought sustainable society.

\subsection{Dwindling Societal Role of Teachers}

In the ancient times, leaders of the various societies depended on philosophers for guidance. In effect, these philosophers who were essentially teachers were the leaders. This subsisted even up to the 1980 s when communities looked up to teachers for assistance in resolving issues which are considered as "nagging". Unfortunately, this grace seems to have departed and shifted from teachers. Today, the clergy particularly those of the Pentecostal Christian extraction, most of whom are self acclaimed, and are in the "God's vineyard" for material gains have taken over. Is not sad to find that Parents/Guardians trust more on these Clergy men than teachers in handling affairs which borders on the education of their wards who are in the schools with these teachers?

\section{Strategies for Enhancing Teachers Roles in Building Sustainable Society}

\subsection{Role of Teacher's Labour Unions}

The roles played by Labour Unions in the educational institutions are such that were directed towards enhancing their members' welfare only. Be that as it may, labour unions and professional bodies within the education sector are advised to broaden their scope of agitations and struggles. The scope deserves to be expanded to cater for improved working environment and those things that will bestow some dignities on teachers.

In spite of the "Red Roof Revolution" of the Edo State Government in Public Basic and Secondary Schools, learning environment still remained sour. The environment is characterized by intimidating 
class size, acute shortage of instructional materials, absence of subventions to schools for basic recurrent cost, weak and compromised administrative machineries, all of which have brought about loss of confidence in the teachers as component of the system.

In the same vein, the condition of service of professionally qualified teachers in the private sector is appalling. They deserve some sympathy. Moreover, the engagement of "whoever" as a teacher in the private schools also deserves attention. Consequent upon the foregoing, the attention of concerned agencies of government is hereby drawn to the practice of indiscriminate approval of private schools, without regards to approved governing rules. The proliferation of substandard and unlicensed private schools ought to be brought to a halt forthwith. This opinion is predicated on the fact that, other sectors such as the health appears to have risen towards tackling similar challenges.

Furthermore, labour unions in the education sector need to spend some of their resources in the evaluation of her members. Clark (1993) reported on union activities in schools in America. According to him, American desire to find better teachers in order to compete with the Soviet Union in 1950s, made the unions to enter into evaluation of their members. The report asserted that, as a result of the union's evaluative efforts, there emerged an increase in more men entering the teaching profession and union increasing their influence. It concluded that; their influence and role in evaluation of teachers offered the profession the respect long overdue.

Since Nigeria leadership has embarked on "change" project. It has become imperative for the labour unions in the educational sector to explore strategies which will make their members to key into the project. In the mean time, one of the changes which teachers should embrace is that of attitudinal change. If teachers are to be true veritable tools for building a sustainable society, their attitudes to work will have to change. The change must be that which is centered on bringing about the attainment of national goals of education, at least as enunciated in the national policy on education.

\section{Conclusion}

Working for sustainable societies is a worthwhile project. Since the efforts for its attainment are the same as those for national development, the teacher is therefore a key player in the exercise. In this regard, the teachers will have to be adequately equipped with the knowledge, skills, techniques and methods that are relevantly required in performance of their roles. Therefore, they as teachers deserve to understand that student learning process must improve over the course of the years. Finally, they must imbibe the spirit of hard work. This is because; a fast growing economy portrays a hard working populace.

\section{References}

Akindele-Oscar, A., Olatunde, J., \& Oyakunle, O. (2013). RASMED Civic Education for Senior Secondary Schools. Ibadan: RASMED Publications Limited.

Clark, D. (1993). Teachers Evaluation: A Review of the Literature with Implications for Educators 
(Unpublished Seminar Paper). Califonia State University at Long Beach.

Federal Republic of Nigeria. (2004). National Policy on Education. Yaba: NERDC Press.

Ezeubor, C. O. (2008). Information Communication Technology (I.C.T) Competences Level of Nigeria Tertiary Institution Teachers as a Challenge to Harness the ICT Gains in Education (pp. 137-143).

Proceedings of First International Conference of Faculty of Education, University of Nigeria, Nsukka.

Hakeen, M. (2015). Selected Teaching Methods. Benin City. Noma Publishing Company Nigeria Limited.

Ibe, E. (2008). Rethinking the Biology Curriculum and its Delivery in an Information Age: Implications for Pre-Service Teacher Preparation.

Iloi, U. (2015). Classroom Masters. In T. E. Umeh (Ed.), Communication Skill Acquisition for Teachers in Secondary Schools. Annual Conference of All Conference in Secondary School Principals Imo State Chapter.

Izogie. (2014). Teachers: Who Are They? University of Benin, Benin City Unpublished Faculty of Education.

Markley, T. (2006). Defining The Effective Teacher: Current Arguments in Education. Journal of Education Theory.

Mogbolu, V. I. (2013). Basic Education Programme Evaluation in Kogi State.

Ngwu, M. (2009). Developing Adult Educators for Community Development in Nsukka District (Unpublished M.Ed Seminar Paper). Faculty of Eduucation. University of Nigeria, Nsukka.

Ngwu, P. (2015). Principals Role in the Supervision of Instructional Delivery Process in Secondary Schools.

Okem, C. P. (2015). Teachers and Teaching in Nigeria: The Way Forward.

Obanya, P. (2014). The Social Engineering Laboratory Paradigm in Universities.

Olulube, N. P., Udogwu, A. E., \& Osaai, A. G. (2006). ICT's and the Effects of Globalization: 21st Century "Digital Slavery" for Developing Countries Myth or Reliability? Retrived from http://www.Descalstate.edu/Strategies

Osadolor, O. A. (2008). Analysis of Adoption Capacity of Modern Information Technology by Senior Secondary Schools in Edo State.

Osadolor, O. A. (2015). Practical Guide to Resourcing in Education. Benin City: Pyramid Publishers.

Sullivan, C. (2001). Rewarding Excellence. Teacher Evaluation and Compensation. Alexandria, VA: National School Boards Association.

Umalele, B. E. (2013). Civic and Human Rights of Citizens. Benin City: Unpublished Lecture Delivered at the 2013 World Teachers Day: Association of Secondary School Tutors, Idia College.

Viederman, S. (1993). A Sustainable Society: What is it? How do we get there? New York: The George Wright Forum Publications.

Yusuf, M. O. (2005). An Investigation Into Teachers: Self-Efficacy in Implementing Computer 
Education In Nigeria Secondary Schools (Vol. 8, No. 2). Meridian, a Middle School Computer Technologies Journal. 